\title{
Violência invisível
}

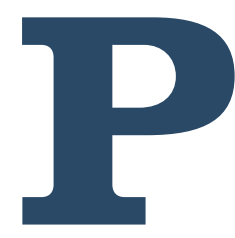

resente muitas vezes de forma imperceptível no ambiente de trabalho, o assédio moral é um tipo de violência que expõe as pessoas a situações ofensivas e humilhantes. De modo lento, porém progressivo, o assédio moral vai se traduzindo em sofrimento, dor e baixa produtividade. Os al gozes corporativos costumam ser gestores autoritários, que abusam de seu poder e das situações de fragilidade de seus liderados. Identificar o fenômeno é um primeiro passo para combatêlo.

por Roberto Heloani FGV-EAESP e Unicamp

Em geral, quando se fala ou se pensa em violência, é inevitável a associação com atos de agressão física. Violência, nesse sentido, éum ato concreto, visível, público, eque normalmente resulta em um dano pal pável, objetivo e observável.

Por outro lado, quando pensamos especificamente em violência no ambiente de trabalho, a primeira imagem que vem à mente é a do assédio sexual. Popularizado pelo cinema comercial em Disclosure, um filme estrelado por Michael Douglas e Demi Moore, ou discutido de forma mais sofisticada pelo dramaturgo e diretor de teatro e cinema David Mamet, em O leana, esse assédio é o abuso de poder que visa à exploração sexual. 


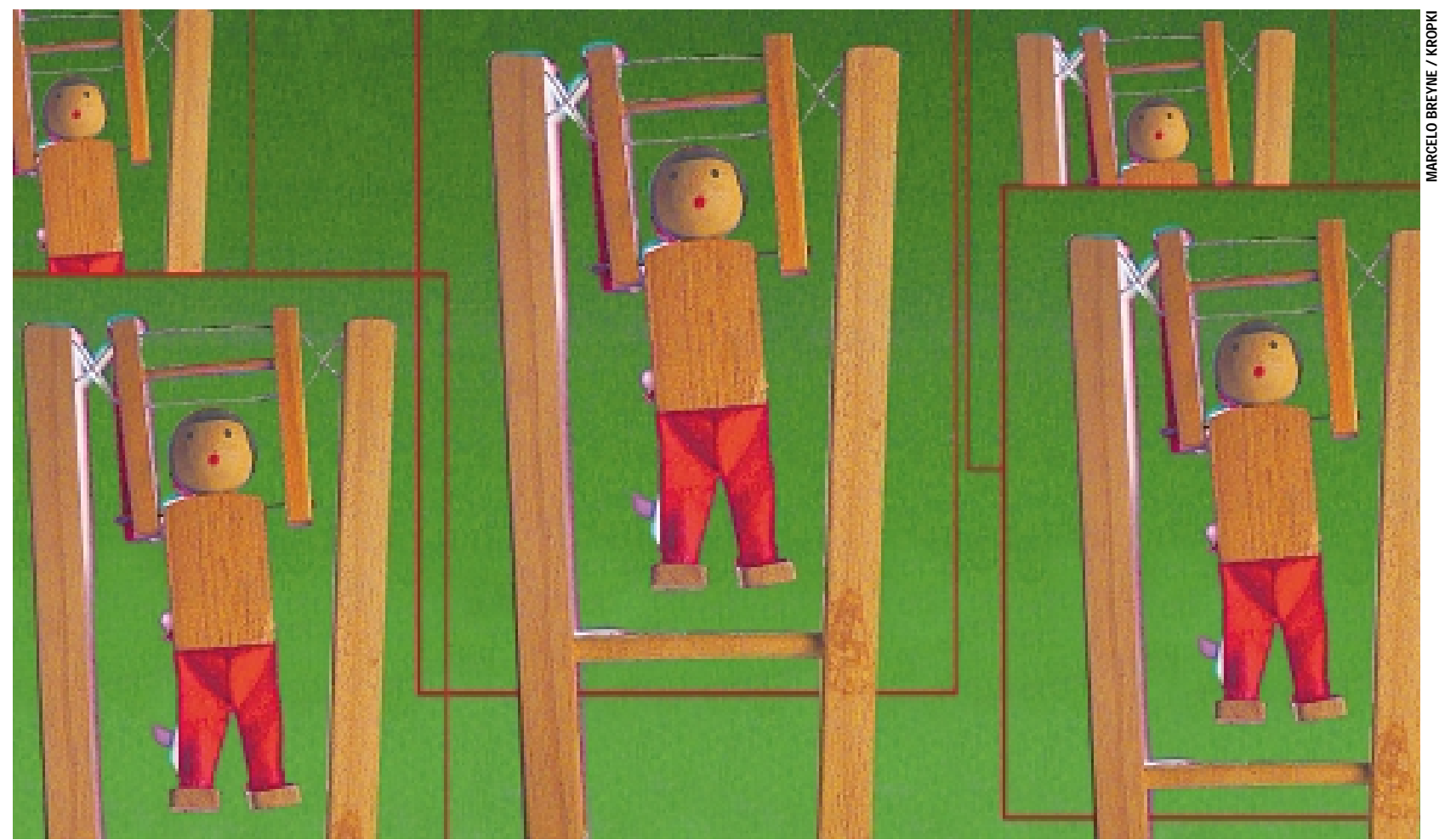

Porém, há muito mais a ser considerado sobre a violência nas relações de trabalho do que somente a violência que se traduz em abuso sexual. Em muitos casos, comuns nas empresas (ver Quadro), o que se nota é uma forma particular de violência, sutil e perniciosa; uma forma de violência que gera vítimas entre indivíduos, grupos e organizações. Damos a essa forma de violência invisível o nome de assédio moral.

É relevante notar que não se trata de um fenômeno recente, pois persiste ao longo da história das relações de trabalho, sempre marcadas por uma grande assimetria de poder. Porém, em nossos dias, com o culto do sucesso profissional e o aumento da competição por cargos e vantagens, tal assédio apresenta-se com força redobrada. Por isso, devemos analisar as principais características do fenômeno e propor formas de combatêlo ou, ao menos, atenuá-lo.

Raízes históricas. 0 assédio moral surgiu como objeto de pesquisa em 1996, na Suécia, pelas mãos de Heinz Leymann. Esse psicólogo do trabalho realizou um levantamento junto a vários grupos de profissionais e detectou um fenômeno que denominou de "psicoterror". Ele também cunhou o termo mobbing (um derivado de mob, que significa horda ou bando), devido à similaridade do "psicoterror" com um ataque rústico, grosseiro.

Dois anos depois, Marie-France Hirigoyen, psiquiatra e psicanalista com grande experiência como psicoterapeuta familiar, popularizou o termo por meio do lançamento de seu livro Assédio M oral, um best-seller que iniciou inúmeros debates sobre o tema, tanto na esfera do trabal ho quanto na familiar.

Com formação em vitimologia na França e nos Estados Unidos, a postura de Hirigoyen é empática em relação à vítima. A especial ista discorda de al gumas teorias psicanalíticas que atribuem boa parte da culpa ao agredido, como se ele fosse conivente com o agressor ou desejasse, inconscientemente, a própria situação de agressão, por masoquismo ou por expiação de culpa. É provável que essa faceta inovadora e humana da abordagem de Hirigoyen tenha sido a responsável pelo enorme sucesso de seu livro.

Compreendendo o assédio moral. De acordo com Leymann, o assédio moral desenvolve-se em uma situação hostil, em que um ou mais indivíduos coagem um 
terceiro indivíduo de tal forma que ele é levado a uma posição de fraqueza psicológica. Para Hirigoyen, 0 assédio no local de trabalho está ligado a qualquer conduta abusiva, em relação a uma pessoa, que possa ocasionar um dano à sua personalidade, à sua dignidade ou mesmo à sua integridade física ou psíquica, e acarretar degradação do ambiente de trabalho ou perda de emprego.

No Brasil, a pesquisadora Margarida Barreto realizou uma ampla pesquisa sobre o tema junto a quase cem empresas, de diferentes setores, na Grande São Paulo. Segundo ela, assédio moral, ou violência moral no trabalho, é a repetitiva exposição de trabalhadores a situações vexatórias, por parte de um ou mais superiores. Maria Ester de Freitas, outra pesquisadora brasileira, observa que o assédio moral está ligado ao esforço repetitivo de desqualificação de uma pessoa e pode, dependendo das circunstâncias, levar ao assédio sexual.

0 assédio moral caracteriza-se pela intencionalidade. Consiste na constante e deliberada desqualificação da vítima, levando-a a uma posição de fragilidade, com o intuito de neutralizá-la em termos de poder. Trata-se, portanto, de um processo disciplinador, no qual se busca anular a vontade daquele que, para o agressor, talvez se apresente como ameaça.

Assédio moral e competitividade. Uma condição que agrava a intensidade e a natureza do assédio moral é a excessiva competição, relacionada ao processo de globalização. Tal condição faci-

lita o surgimento de formas nocivas de tratamento por parte de gestores, que fazem uso de seu poder para humilhar as pessoas sob seu comando.

Muitas vezes esses agressores são bem vistos por seus chefes devido à sua capacidade de tomar decisões difíceis e polêmicas. Costumam ser admirados por sua eficiência e eficácia, apesar da arrogância com que tratam seus subordinados. Tais gestores comumente possuem traços narcisistas e destrutivos. Sentem-se inseguros quanto à sua competência profissional e podem exibir, por vezes, traços paranóicos, projetando nos outros sua "sombra", ou seja, aquilo quenão conseguem aceitar em si mesmos. Agem com desconfiança em relação às atitudes al heias e têm grande dificuldade para aceitar críticas. Costumam ser hipersensíveis e exagerar o risco presente em diversas situações. Com isso, supervalorizam seu próprio trabalho e fortalecem sua auto-estima. Ambiciosos e invejosos, procuram constantemente aproveitar-se do trabalho alheio: apropriam-se das realizações de outros para montarem uma pseudo-imagem de si próprios como verdadeiros "salvadores da pátria".

Vítimas silenciosas. 0 assédio moral costuma surgir com pouca intensidade. Porém, aos pou cos vai se propagando e a vítima passa a ser alvo de um número crescente de humilhações e de brincadeiras de mau gosto.

As vítimas temem fazer denúncias formais, com medo de retaliações, como mudanças desvantajosas de função e local ou até a demissão. Além disso, denúncias podem tornar pública a humilhação pela qual passaram, aumentando ainda mais seu sofrimento.

Embora seus agressores tentem desqualificá-las, as vítimas não costumam ser indivíduos doentes ou frágeis. São pessoas que tomam, de forma consciente ou inconsciente, posições de enfrentamento, al gumas vezes questionando privilégios ou situações injustas. Com isso, tornam-se os alvos das agressões. Isso ocorre justamente por não se deixarem dominar, por não se curvarem.

\section{O assédio ou violência moral no trabalho costuma} gerar patologias em suas vítimas, na medida em que faz com que elas acreditem ser exatamente o que seus agressores pensam que sejam.

Com o tempo, o próprio assédio pode gerar patologias nas vítimas, à medida que faz com que elas acreditem ser exatamente 0 que seus agressores pensam, ou desejam, que sejam: desatentas, inseguras, incompetentes e frágeis. Em alguns casos, a vítima pode entrar em processo 


\section{A maior dificuldade em relação ao}

\section{tratamento do assédio moral é justamente}

sua "invisibilidade" e o alto grau de subjetividade envolvido na questão.
Em um tipo de agressão paulatina e quase invisível, quando a vítima de fato percebe a situação, o processo destrutivo já se estabeleceu, eventualmente sem possibilidade de reversão. Essa atitude de aparente passividade, de ausência de ação, é vista em nossa cultura como um atributo feminino, o que agrava o qua- depressivo, prejudicando seu desempenho no trabalho e realizando a profecia induzida por seu algoz.

Homens e mulheres. As pesquisas apontam que as mulheres são as maiores vítimas do assédio moral. Também são elas que mais procuram ajuda médica ou psicológica. Para o homem, a situação de assédio moral ganha contornos específicos, pois fere de forma diferenciada sua auto-imagem. dro depressivo se a vítima for um homem, pois enfraquece ainda mais sua auto-estima. No caso masculino, tornar pública a humilhação equivale a admitir a impotência diante dos fatos. Por isso é comum o aparecimento de sintomas como úlceras, disfunções sexuais e cefaléias.

Coibindo o assédio moral. Há dois níveis de medidas que podem e devem ser tomadas para se coibir, ou até mesmo erradicar, 0 assédio moral: o primeiro nível diz respeito a

\section{As marcas da violência}

\section{A história de Sílvia}

Sílvia é uma executiva bem preparada: cursou diversas especializações e fez um MBA no exterior. Bonita, com aproximadamente 40 anos, trabalha em um grande banco nacional como analista de sistemas. Recentemente separada, e mãe de um único filho, portador de paralisia cerebral, depende fortemente do trabalho para subsistir. Devido à condição do filho, ocasionalmente precisa de autorização de seu superior para levar o menino a uma clínica de tratamento.

Seu chefe constantemente a sobrecarrega com inúmeras tarefas em curto espaço de tempo, contribuindo para uma condição de permanente estresse. Embora não negue as autorizações solicitadas, 0 chefe de Silvia não perde a oportunidade de rebaixá-la. Em várias ocasiões, questiona rudemente sua liderada: "Se você não quer trabalhar, por que não dá o lugar para outro?".

A situação permanente de pressão e constrangimento faz com que Sílvia viva em constante estado de angústia, próximo da depressão.

\section{A história de Celso}

Celso é um jovem ambicioso, diplomado em computação e em administração de empresas por uma conceituada universidade. Por não possuir experiência, experimentou dificuldade para ob-

ter seu primeiro emprego. Percorreu várias agências de empregos, passou por numerosas entrevistas, até que foi chamado para integrar a equipe de marketing de uma grande empresa da área de bebidas.

Começou a trabalhar com entusiasmo, porém seu ânimo foi arrefecendo à medida que seu chefe passou a tratá- lo rudemente com frases constantemente repetidas: "Bem se vê que você não tem experiência!"; "Puxa, você é mesmo difícil! Não consegue aprender as coisas mais simples!"; "Até uma criança faz isso, só você não consegue!"; "Você me enganou mesmo com seu currículo. Não consegue fazer metade do que colocou no papel".

Celso vem se esforçando, mas já se encontra sob tal pressão que perde sua habilidade natural para realizar com presteza suas funções. Seu chefe não perde a oportunidade para desqualificá10 ainda mais, aparentemente com o objetivo de fazê-lo deixar 0 emprego. "É melhor você desistir! É muito difícil, e isso é para quem tem garra! Não é para gente como você".

Celso começa a sentir cansaço e tensão constantes no trabalho, com momentos de lapsos de memória. Em casa, evita conversar com a esposa sobre o trabalho e, à noite, sofre de insônia. Anseia pelos finais de semana e sente uma forte depressão quando a segunda-feira se aproxima. 
ações que as próprias empresas podem tomar; o segundo diz respeito a uma compreensão mais abrangente das variáveis que determinam o fenômeno.

Do ponto de vista das empresas, a criação e a aplicação de códigos de ética é certamente uma conquista importante, embora não suficiente. Além de tais códigos, poderiam ser criados mecanismos para dar ao funcionário agredido o direito de denunciar a agressão de que tenha sido vítima, por escrito e sigilosamente. Assim, a vítima poderia utilizar caixas postais ou urnas para ter seu anonimato garantido.

Mas é preciso também rever as condições que determinam o exagerado ambiente de competição. Isso representaria um passo efetivo no processo de humanização do trabaIho. Em outras palavras, a discussão do assédio moral deve levar as pessoas a refletirem sobre a condição sistêmica da questão: não se trata de problema individual, mas de um problema que envolve interações sociais complexas e a conquista de direitos fundamentais.

Esses direitos, é conveniente notar, já fazem parte do aparato legal brasileiro. Porém, a maior dificuldade em re- lação ao tratamento do assédio moral é justamente sua "invisibilidade" e 0 alto grau de subjetividade envolvido na questão. A comprovação da relação entre a conseqüência o sofrimento da vítima - e sua causa - a agressão -, indispensável na esfera criminal, nem sempre é aparente, na medida em que tais humilhações são mormente perpetradas "com luvas", ou seja, sem deixar as digitais do agressor.

No entanto, apesar dessas dificuldades, esforços vêm sendo realizados em diversos países, inclusive no Brasil, para tornar a prática do assédio moral passível de pena. Mais do que a lei, no entanto, é preciso criar a consciência geral de transparência, contribuindo para que o ambiente de trabal ho seja saudável e adequado ao desenvolvimento das potencialidades dos indivíduos.
Roberto Heloani
Prof. do Departamento de Administração da Produção e O pera- ções da FGV-EAESP
Prof. livre-docente em Teoria das Organizações na Unicamp
E-mail: jheloani@fgvsp.br

\section{A vida, a arte e a vida}

Cinema e realidade vivem intensa relação. Desde que o primeiro foi inventado, a segunda nunca mais foi a mesma. No início era o cinema que imitava a vida. Agora, é a vida que imita o cinema. 0 ano de 1994 foi aquele em que dois filmes, o popularesco Disclosure, estreado por Michael Douglas e Demi Moore, e o mais respeitado, e menos conhecido, Oleanna, escrito e dirigido por David Mamet, abordaram o difícil tema do assédio. Ambos ajudam-nos a refletir sobre os impactos do fenômeno no ambiente de trabalho.

\section{Disclosure (1994)}

Direção: Barry Levinson

Distribuição: Warner Bros

0 filme aborda a problemática do assédio moral pelo ângulo de maior apelo: 0 sexual. Entremeado à intriga de poder, 0 sexo é a arma que Meredith Johnson (Demi Moore) utiliza para atacar seu ex-parceiro e concorrente profissional,Tom Sanders (Michael Douglas). 0 filme subverte a lógica "chefe oportunista explora funcionária". A história mostra uma mulher em posição de maior poder coagindo um subordinado, isso por conta de uma relação amorosa mal resolvida. Em ritmo de triller, a história contrapõe tramas pessoais e organizacionais. Enquanto a família deTom é ameaçada, o presidente de sua empresa tem um papel ambíguo, encobrindo condutas antiéticas.

\section{Oleanna (1994)}

Direção: David Mamet

Distribuição: Alpha Filmes

Oleanna, baseado em peça do mesmo nome, é um filme mais sensível e intelectualmente superior. No centro da trama, a palavra e sua manipulação. Em uma escola norte-americana, um professor é acusado de assédio por uma aluna. 0 filme levanta a dúvida sobre quem é 0 agressor e quem é 0 agredido? Explorando nuanças e ambigüidades das situações, esta obra do dramaturgo Mamet foge de interpretações simplistas e unilaterais. Por trás da história de vítima criada pela aluna, há uma edição bem articula$d a$, e talvez manipulada, da realidade. 